\title{
Sheffield

\section{Men researching men in prison: the challenges for profeminist research}

COWBURN, M.

Available from Sheffield Hallam University Research Archive (SHURA) at: http://shura.shu.ac.uk/605/

This document is the author deposited version. You are advised to consult the publisher's version if you wish to cite from it.

\section{Published version}

COWBURN, M. (2007). Men researching men in prison: the challenges for profeminist research. Howard journal of criminal justice, 46 (3), 276-288.

\section{Copyright and re-use policy}

See http://shura.shu.ac.uk/information.html 


\section{MEN RESEARCHING MEN IN PRISON: THE CHALLENGES FOR PROFEMINIST RESEARCH}

\section{MALCOLM COWBURN}

Senior Lecturer in Social Work, University of Bradford 


\title{
Men researching men in prison: the challenges for profeminist research
}

\begin{abstract}
This paper addresses epistemological and practical issues in conducting research in male prisons from a profeminist standpoint. It considers the role of the male researcher in engaging with prison masculinities and a sexist prison culture. It gives examples of difficulties in managing the profeminist research role in the wider prison and it highlights difficulties that may occur within in interviews. Adapting Goffman's (1970) strategies for inmate survival it concludes that the most appropriate researcher strategy for not compromising the standpoint of the study and yet sustaining a project in prison may be for the researcher to (reflectively) 'play it cool' (Goffman 1970; p. 64).
\end{abstract}

Keywords: prisons, masculinities, profeminist research

\section{Introduction}

This paper considers the challenges of conducting profeminist research with men in prison. It is based on my recent experience of undertaking life history research with incarcerated male sex offenders and builds on my earlier prison based research (Cowburn, 1998). In order to maintain confidentiality I use pseudonyms when referring to the men that I interviewed and I do not name the prison where the research occurred.

Initially I outline the project from which this paper is developed. I go on to describe the standpoint from which the study was conducted. Understanding 
masculinities and then Sexism in prisons are the next two areas addressed. I conclude the paper by considering issues for the male researcher in prison and how profeminist research can be sustained in this environment.

\section{Outline of research project}

Nine men imprisoned for sex offences told me their life histories. They were serving sentences of between four and ten years. Six of the men had offended against children and three had offended against adults. Only one of the men had previous convictions for sexual offences. All of the men were white and aged between 25 and 61 years old at the time of interview. All interviews took place in a category $\mathrm{C}$ prison over two separate periods of ten days. The men told me their life histories from their earliest memories to their current situation. Following Connell (1995), the interviews were semi-structured, using life transitions (for example entry to school, work) as prompts for memories. All of the interviews were made up of many sessions. The boundaries of each session were prescribed by prison routines. The interviews lasted between four and seven hours in total and most of them lasted more than one day.

\section{Epistemological Standpoint and empirical practices of the present study}

Strong objectivity requires that we investigate the relation between subject and object rather than deny the existence of, or seek unilateral control over, this relation. (Harding, 1991; p. 152)

Liebling and Stanko (2001) have recognised that researching crime and violence is inevitably imbued with 'squalid politics and ethical predicaments' (p. 421). 
They note that, although the vitriolic debates within 'theoretical criminology' concerning the nature of objectivity have abated (p. 426), there is still a 'moral mission' for criminologists to disclose 'one's political allegiances' (p. 426). In this context they note that 'the emotional and methodological dilemmas in managing allegiances and alliances' are of particular concern in studying violence ( $\mathrm{pp}$ 426427).

In her critique of the natural science paradigm, Harding (1991) highlights that the objectivity of much (social) scientific research is developed from the unacknowledged standpoint of white middle-class heterosexual men; as such it is a 'weak' objectivity because it fails to recognise its specific cultural location in the production of knowledge. She suggests that to achieve 'strong objectivity' the researcher or theorist must explicitly recognise and theorise their own standpoint and how this has informed the research process. Hearn (1998) has suggested that most social theory has been written by men without explicitly recognizing their gender as part of their standpoint or preconceptions or prejudices. He (Hearn, 1998) identifies a continuum of six types of discursive practice involving men theorising about men. His first category is 'Absence, fixed presence, and avoidance' in which either the topic (men) or the author are absent, avoided or present yet non-problematic. At the other end of the continuum in his typology, Hearn (1998; p. 801) places 'Critique' as a self-conscious and politically informed response from certain male theorists:

Critique thus combines a number of elements: a critical relation to the topic, encompassing a self-reflexivity of the author and the topic, and the consideration of the social bases of knowledge; a commitment to the 
political emancipation of both women and men; and where appropriate, empirical inquiry not just assertion and speculation.

This position makes explicit the preconceptions and prejudices of the researcher. It also carries the necessary explicit reflexivity suggested by Harding (1991). Additionally, it strongly asserts the necessity of explicitly incorporating a social and political stance, a position with which Liebling and Stanko (2001) would concur.

I undertook the present study from a pro-feminist standpoint (Pease, 1997, Hearn, 1998, Pease 2000). Such a standpoint is the male complement of feminist standpoint. Key features of it are: familiarity with feminist critiques of patriarchy and male power, reflexivity and a desire to change dominant forms of male behaviour. As such, it incorporates the elements of critique identified by Hearn (1998) and this embodies an epistemological position that is critical of dominant forms of knowledge. My standpoint developed from and through my work as a probation officer working with perpetrators of sexual violence. In this work, other workers and I identified the values that underpinned our practice (Cowburn, 1990, Cowburn, 1993, Cowburn and Modi, 1995); these values were influenced by a feminist analysis of patriarchal power and male sexual behaviour. A critical understanding of male power and the ways it was used to harm others were key elements in our value-bases. A significant implication of these values was that dominant forms of knowledge about sex offenders were questioned: the male sex offender was not just construed as being part of a 'deviant' population, 
but also as part of the continuum of men and their sexual behaviours identified by Kelly (1988). As such, a profeminist standpoint incorporates both anti-sexist perspectives on male behaviours and also insights from feminist epistemologies. Thus, it reflects on the nature of knowledge construction and a key part of this involves consideration of who is undertaking research with whom, how and where.

However, although the epistemological standpoint of my study was (relatively) clear the practical and personal consequences of such a standpoint were developed as the project progressed. Although the ostensible focus of attention was on the life histories of the imprisoned men, the context in which the research took place forced me to reflect on the implications of undertaking a study from a standpoint that is critical of dominant forms of male behaviour. Carrabine and Longhurst (1998) have highlighted that a full understanding of how masculinities are enacted in prisons can only be obtained by considering both the behaviours of prisoners and also prison staff. Daily I encountered behaviours of male staff that were both misogynistic and hostile to any form of masculinity that that did not appear to subscribe to the dominant way of behaving as a man. Developing empirical practices that were congruent with my epistemological standpoint and yet did not jeopardise the research project required me to reflect on how to behave in an ethical and anti-sexist manner that did not cause me to be viewed as alien by the majority of men working in the prison. 


\section{Understanding the dominance of (some) men}

Within the literature of gender there has developed a growing concern with how gender is 'performed' (Butler, 1989, Butler, 1993, Clatterbaugh 1998, Connell 1995). Masculinities and the men that perform them vary according to age, race, class, sexualities, physical and learning abilities. However, in western societies, Connell has suggested that there appears to be a dominant - hegemonic - form of masculinity (Connell, 1995). He (Connell, 1995; p. 77) describes hegemonic masculinity as:

... the configuration of gender practice which embodies the currently accepted answer to the problem of the legitimacy of patriarchy, which guarantees (or is taken to guarantee) the dominant position of men and the subordination of women.

Here his focus is on 'practice' (what men do) and it specifically concentrates on current behaviours and thus does not make ahistoric universalist claims. However, although this concept has been very influential in the 1990s in theorising male dominance, it has recently come under critical scrutiny. Jefferson (2002) for example, has shown that whilst Connell was clear in his formulation of hegemonic masculinity as fluid and contingent, some of his 'followers' have reified this term and use it to refer (albeit vaguely) to one particular form of masculinity. Addressing similar problems Hearn $(2004 ; 58)$ has summarised the main problems with 'hegemonic masculinity' as a critical concept:

... there are three unresolved problems. First are we talking about cultural representations, everyday practices or institutional structures? Second, how exactly do the various dominant and dominating ways that men are tough/aggressive/violent; respectable/corporate; controlling of resources; 
controlling of images; and so on - connect with each other? Third, why is it necessary to hang on to the concept of masculinity rather than, say, men's practices ... when the former concept has been subject to such critique ... and is in use in such very different and sometimes confusing ways?

Thus whilst 'hegemonic masculinity', as a critical idea, has provided useful insights into the dominance of a certain group of men in certain contexts and at specific times, it has not, despite Connell's intentions, had sufficient clarity of focus in relation to what specific groups of men do to maintain their dominance. Hearn (2004; p. 60) has suggested that rather than focus attention on an illdefined abstraction, critical attention should be focussed on how men sustain their hegemony.

\section{Sexism in prison}

Prison research over a number of years has highlighted that male staff (particularly uniformed staff) did not want women to work in prisons. In the early 1960s Terence and Pauline Morris (1963; p. 9) noted:

... some staff members felt a masculine antipathy towards a professional woman. Work was for men, and prison work was for strong men; a woman's place was at home exemplifying the idea of "Küche" and "Kinder", if not of "Kirche".

Other researchers in prison have noted a similar range of hostile attitudes and behaviours towards women from both prisoners and prison staff (for example Genders and Player; 1995; pp $42-43$ \& pp.95-96; and Scully, 1990; pp. 11-13). In 1995 an Industrial Tribunal awarded a female prison officer $£ 15,000$ compensation for injury to feelings after winning her sex discrimination case against the Prison Service (Equal Opportunities Commission, 1995). The Tribunal noted that: 
The culture of the prison officers ... was that sexual jokes and innuendo were the norm amongst many officers. ... However, we find the culture of sexual jokes and attitudes towards women was a problem. Undoubtedly some of the prisoners could use terms including sexual remarks in order to attempt to shock: that is something which prison officers have to deal with and live with. It does not follow that the first respondents [The Home Office] could not take steps to alter the conduct of officers where necessary in our view. (The Industrial Tribunals, 1995; pp3-4 cited in Cowburn, 1998; p. 238)

In my own study, a few years ago, women workers in prison described as commonplace a wide range of sexist and sexually harassing behaviours (Cowburn, 1998; pp 247-248 \& p. 241).

Crawley's (2004; pp190-197) more recent study of 'prison work' in six public sector male prisons identifies very similar attitudes in current male prison staff. The reasons for objecting to women in prison ranged from essentialist arguments that their place was in the home, to more expedient justifications such as they could not strip-search a man or take an equal part in violent confrontations with prison inmates. The hostility towards women staff in prisons is most clearly marked in sexist attitudes and behaviours of male staff. Almost ten years after the Hoare Industrial Tribunal ruling, Crawley (2004; p. 190) found that little had changed:

Although women officers are welcomed into the service at the recruitment stage, some find that once on the landings of male prisons they are not fully accepted by some of their male colleagues. ... this lack of acceptance is often made explicit. Female officers may find themselves at the receiving end of sexist and degrading jokes and remarks; at the same time however they may find they are 'protected' by the male officers with whom they are working. Perhaps unsurprisingly, most women officers resent both these responses, not least because they indicate that as prison officers they are seen as less capable than men. 
A female senior officer provides a vivid picture of male sexist bullying of young female officers:

Most men readily accept that women play a very important role in the prison setting, 'cos we can defuse situations, especially as the majority of inmates wouldn't dream of hitting a female and would probably go to a female officer's assistance instead. But you get the odd chauvinist pig who thinks a woman belongs in the kitchen barefoot. And it's a form of bullying. [What sort of things does this kind of officer say?] They say 'You stay in the office, we'll go out on the landings. You're only a split-arse. You put the kettle on!' And funnily enough, its always the same terminology - 'split-arse'. To me it's not just sexual harassment, it's bullying, 'cos they wouldn't do it with me. They pick their victims; they're a bit like lions aren't they? The ones you see on the telly stalking zebras and that. They pick out their prey ... [They think] 'we'll pick her, she'll cry'. (Crawley 2004; p. 191 emphasis in original)

In considering this behaviour Crawley (2004; pp192-197) suggests that the presence of women workers in prisons potentially removes, for male officers, a key way of being male; she notes:

Women disrupt the close association between the prison officer role and the performance of masculinity; if women are allowed to do the job, and if they can do it as well as their male counterparts, the job is 'no longer a viable resource for constructing masculinity' (Martin and Jurik 1996: 175). (Crawley 2004; p. 195)

It would thus appear that sexist harassment of women workers plays a central part in maintaining the hegemony of men in prisons

\section{Male researcher in prison: the challenge of non-sexist practice}

As a man working in prisons with male prisoners, it can be easy to ignore or to minimise the presence of and effect of sexism. In an earlier study of prisons, I 
asked male workers if they were aware of sexism in prisons. In general male workers showed little awareness and most participated in what they considered

to be male humour. A few male workers considered how to respond to sexism, however, where they did not collude with it, they remained silent (Cowburn, 1998). The challenge for male researchers of non-sexist research practice is different to those facing prison workers in so far as (most) researchers do not work full-time for long periods in prisons and are not part of the staff group of the prison. In this section I consider how I managed my relationships with the male prison staff also how I was challenged by the process of interviewing the prisoners.

\section{Male researcher: just one of the boys?}

Goffman (1970; p. 61-64) has described the various survival strategies adopted by new inmates in total institutions (1), and although as a researcher in prison I could not consider myself to be an 'inmate', many of the strategies he identifies have resonances and relevance to how I thought about and managed my role as male researcher. The main strategies identified by Goffman (1970; p. 61-64) are: 'situational withdrawal', 'intransigent line', 'colonisation', and 'conversion'. For a man critically researching male (sexual) violences and also attempting to conduct his research in an anti-sexist manner, prison can appear a very hostile environment. The strategy of 'situational withdrawal' may appear attractive in these circumstances. Goffman (1970; p. 61) describes this process: 
The inmate withdraws apparent attention from everything except events immediately around his body and sees these in a perspective not employed by others present...

Whilst this strategy may offer some kind of protection for a new inmate, it would, if adopted exclusively by a researcher, condemn the research project from the outset. Similarly the 'intransigent line' is not feasible for the researcher seeking the co-operation of prison staff. However, both 'colonisation' and 'co-operation' are attractive and also worrying strategies for the male researcher in prison. Both approaches require an uncritical adoption of the dominant culture within the prison (Goffman 1970; $p$ 62-63). The attractiveness of these strategies for the male researcher is that by becoming assimilated into the prison culture it may make it more accessible to him. The dangers, particularly for a researcher adopting a pro-feminist standpoint and thus seeking to behave in an anti-sexist manner, are that this orientation (particularly in relation to issues of power and gender relations) may well be compromised or lost through being assimilated into the dominant culture. In concluding his discussion of survival strategies, Goffman (1970; p.64) comments that inmates rarely adopt a single strategy but, at different times, may use all of them; this he calls 'playing it cool'

The alignments that have been mentioned represent coherent courses to pursue, but few inmates seem to pursue any one of them very far. In most total institutions, most inmates take the tack of what some of them call 'playing it cool'. This involves a somewhat opportunistic combination of secondary adjustments, conversion colonization and loyalty to the inmate group, so that the inmate will have maximum chance, in the particular circumstances, of eventually getting out physically and psychologically undamaged. 
My research had to fit round prison routines. On arriving at the prison each day, I had to check-in with the security officers at the prison gate. This was the first place where I was tested by the male uniformed staff. Especially in the early part of the research, I would be subject to questioning and often had to wait ten or fifteen minutes before I gained access to the prison. In many ways, this was understandable, but there was variety in the way I was treated; some officers clearly wanted to let me know that they were in control of my access to the prison and that they could seriously restrict the contact time that I had with each man. Perhaps during these moments I used the strategy of 'situational withdrawal'. I remained quietly disengaged from provocations that were offered to me and this seemed to be effective in that I was rarely delayed for long periods.

However, there is an additional consideration to bear in mind when thinking about waiting at the gate. Most of the prison officers on the gate were male. As a male researcher I was not subject to sexist badinage or hostility whilst I was waiting to be taken into the prison. Genders and Players (1995), and Pauline Morris (1963), women researchers in prison, report very different and more personally difficult experiences.

On each visit, I was escorted from the prison gatehouse to the Psychology Department. As the research progressed, I became a familiar figure at the prison and was generally treated well by all of the prison staff that I encountered. Perhaps it was in these moments that I came nearest to being 'converted'. 
However, this was not a pervasive experience. Throughout my time in the prison I used a range of strategies: the most difficult tension to manage was where I was faced with issues that directly confronted my anti-sexist value-base.

Once inside the prison I could not move anywhere without an escort. There was no immediate access to toilets, thus in the interviews I scheduled periodic comfort breaks. I had to be escorted by a member of the Psychology team to and from the toilet. On one occasion where a member of the psychology department allowed me to go unaccompanied to the toilet, I was apprehended by a uniformed Senior Officer (SO) and asked to account for why I had no escort. Unfortunately, the member of staff that allowed me out unescorted was female. The SO said he would have to have word with her and 'smack her bottom'. This could have been taken as an invitation to join in sexualised banter to cement a male bond (colonisation); I did not respond (strategic withdrawal) but informed the staff member of my encounter with the SO.

During my second batch of interviews the prison was rocked by scandal. A female prison officer had been found with a prisoner in a shower block; she was hiding. It was apparent that she had had a sexual relationship with the man. Additionally, the prison officer was married to a Governor of another nearby prison. This matter was reported salaciously in The Sun for a number of days. Initially no comments were made to me about it, but I gradually began to encounter (be invited to share in) oblique sexual jokes. Again, I refused to 
participate and, being an outsider I was able to feign ignorance about what was being alluded to (strategic withdrawal).

The difficulties of behaving in a non-sexist way in the daily conduct of research in a prison are many; the main strategy that I adopted when confronted with overt sexism was one of 'strategic withdrawal'. However, at other times I was able to respond to prison officers in a positive and friendly way as we met at the prison gate either coming in to the prison or leaving (colonisation/conversion). Whilst at times I wished to confront (intransigent line) sexist attitudes and behaviours, I did not do so because I needed the co-operation of the prison staff to be able to complete my research. Liebling and Stanko (2001; p. 425) highlight the dilemmas associated with the 'anxieties about losing access to one's research site'. They (Liebling and Stanko 2001; p 427) specifically highlight the work of Westmarland (2001) who struggled with the dilemma of whether to report police violence observed during a research project and thus jeopardise the project . Overall maybe my strategy was one of 'playing it cool' (Goffman, 1970; p. 64) without colluding with sexist attitudes and behaviours.

\section{Male researcher interviewing men in prison}

In this section I consider the challenges for the male researcher of listening to offence accounts where the research participant persistently denies responsibility for his offending and construes his victim as being responsible for her own abuse. 
Colton and Vanstone (1996; p. 5) have noted that, as researchers, ...we had to consciously inhibit our natural reactions to some of the discourse of the men and to limit overt challenging of attitudes and distorted thinking in order to facilitate a process that enabled their stories to be told.

In his life story, Martin causally linked his father leaving him and his (Martin's) subsequent abuse of his daughters. When he spoke of how his father had supported him and his brother after their mother left the family home, he spoke with affection and love. However, shortly afterwards he recounted how his father left him and his brother to be cared for by paternal grandparents, whilst his father moved in with a 'girlfriend'. In telling this part of his story, Martin became very distressed and cried profusely. He spoke bitterly of feeling betrayed and abandoned. Later in his story, he described how he sexually abused his daughters. His understanding was that they each wished to have sex with him. He said that he did not want reject his children like his father had rejected him (by not acquiescing to Martin's desire to stay with him). He said that he did not want his daughters to feel the pain of rejection that he felt because of his father's actions and so he went along with his daughters' demands. He started abusing each child when they were approximately ten years old and continued until each daughter was in her early twenties. In my previous work as a probation officer, I heard many similar justifications from men who have abused their children, and it was part of my role in interview or groupwork to deconstruct their story and reveal inconsistencies in order to help them recognise that there was another 
version of the events. In my role as researcher, it was not appropriate for me to challenge the story that I was hearing. However, as he elaborated his story I found it impossible to listen passively. The section below illustrates the problem and how I engaged with it:

Martin: ... I tried [to be a good father] ... well I suppose more or less, you overdo the love and it goes wrong. I loved them as much as I could and it went wrong. Erm ... I let it go wrong, I allowed it to. Whatever ... way you want to put it. I know it shouldn't have happened, and I knew what I was doing. I can't say it was impulse, it certainly wasn't that. I just gradually allowed it to happen, although once I got into it I didn't like it, and I thought I've got to stop this, but that didn't succeed, mostly because of this rejection feeling I had. If I hurt them ... course I never used to smack them or anything like that, l've never been a violent person with them ... er ... I gave in easy, too easy.

MC: A thought came to me, thinking about what you were saying, did you have any parental authority, how did you exercise that?

... if one of your children was doing something that was going to put them in danger, and they wanted to do that because they wanted to, how would you cope with that?

Martin: Oh, l'd warn them of the danger, and make sure that the ... Mind you, you've got to remember I was at work, so a lot of the time they were on their own. But if I did see anything dangerous, I would point out the danger. ...

MC: So if they were doing something dangerous, immediately dangerous, ... how would you cope with that?

(Pause)

MC: If they wanted to go skateboarding in the middle of the road?

Martin: (starts, shocked) Uh, oh well, you say no, don't do that.

MC: How do you stop them, do you have an authority?

Martin: Yes, if you were in my position ...

MC: Because what l'm thinking is ... 
Martin: I'd probably take the skateboard off them, lock it up.

MC: What l'm thinking is trying to make a link with that and rejection. Because if they say ... if they experience you taking the skateboard off them as rejection, would that mean that you would give them the skateboard?

Martin: No because they would probably have the hump instead of trying to talk me round, that's how l'd look at that, they'd probably have arseache because l'd took the skateboard off them. It's a different situation. It's not emotional ... its not so emotional as what I was trying to stop.

MC: Explain that a bit more to me.

Martin: That's ... that's ... what you are saying ... how can I explain that. That's a danger to them where they could lose their life, so you've got to do something. But where it doesn't ... where they assure you everything's all right, then that's a different ...

MC: But if they assured you that they could control the skateboard?

Martin: Err ... not in the middle of the road, l'd still try and stop them from doing that. I wouldn't be wild about it. I should have to beg them to see sense, from doing that sort of thing. I mean they've got to know the danger as well, of skateboarding in the middle of the road, so they've got to see the danger as well. I don't think that's a very good scenario, that's not, because then they must know, their life's in danger if they do a thing like that.

Gradually, my irritation at his construal of abusing both of his daughters for a period exceeding ten years as a sustained act of excessive love became too much to bear. Pickering (2001) has highlighted the importance of considering the effect of emotions in the interviewing process. My response in the above interview was to use oblique ways of trying to highlight the untenability of Martin's justification for his sexual offending. However, it is also clear that I was using my power and authority to direct the conversation and (eventually) to make him uncomfortable. It may have been that because of the unacknowledged power 
discrepancy between us that he allowed the conversation to continue. It may also have been that the absence of a direct confrontation allowed both of us to proceed with the interview but the situation did become increasingly uncomfortable for both of us.

\section{Towards profeminist research practice in prisons}

To have values or not to have values: the question is always with us. When sociologists undertake to study problems that have relevance to the world we live in, they find themselves caught in a crossfire. Some urge them not to take sides, to be neutral and do research that is technically correct and value free. Others tell them their work is shallow and useless if it does not express a deep commitment to a value position. (Becker 1967)p. 239 cited in (Liebling 2001; p. 472)

In her 2001 paper Alison Liebling reflects on the dilemma 'Whose side are we on?' when undertaking prison-based research. She considers issues relating to sympathy, power and credibility in competing perspectives and politics in prison

research. Much of her discussion assumes a politicised polarity within the prison context - the researcher is (potentially) either on the 'side' of the prisoner or the prison staff/management. The researcher can either choose allegiance, usually predicated on political and theoretical orientation, or can strive towards a '(Mild) Social Constructivist, Adaptive Theoretical Approach' (Liebling 2001; p. 481). The research project described here does not fit easily on either side of a politicised polarity. In researching sexual violence a number of polarities immediately spring to mind - for example 'victim or offender'; 'sex offender or ordinary man'. The polarities of prison research that Liebling (2001) has identified are less relevant. However, the profeminist standpoint outlined at the 
beginning of this paper clearly implies allegiances with feminist theory, with women and men in subordinated groupings and thus with victims of sexual crimes rather than with the perpetrators of such crimes.

Yet these allegiances are not always simple and the challenge of producing credible social science research needs some consideration. Liebling (2001; p. 482, citing the work of Cohen (1998) asks:

How do we define intellectual integrity; and is it possible to have what Stan Cohen described (Cohen 1998: 99) as a 'double loyalty', both to political and social values, and to social scientific research - and to keep then in any sense distinct?

She goes on to explore further the relationship between values and social science research:

To believe in the possibility of some social science truths (for example, is there brutality in a local prison and what form does it take?) does not necessarily imply that there is a fixed reality or 'master narrative' at the level of explanation. (emphasis in original)

She (Liebling 2001; p. 481), following Cohen (1998) and Bottoms

(2000),distinguishes the role that political and social values have at different points in the research process and states that:

... we need to balance the practice of theory with the practice of empirical social science, in order to improve our understanding of the (in the end real, empirical) social world, albeit one we all perceive and interpret from a standpoint of some sort...

This paper has explored difficulties involved in sustaining congruence between 'the practice of theory' and 'empirical practice of social science' in a male prison. 
The challenges for the (profeminist) male researcher researching men in prison occur at both theoretical and an empirical level. At the theoretical level the issue of whose knowledge is most influential in shaping the interpretative framework through which the narratives of these men are understood is of great importance (Harding 1991; Cowburn, 2005). Harding (1991) and Hearn (1998) have asserted the importance of identifying, integrating and understanding the standpoint from which the research was undertaken and how this has shaped the findings of the research. However, the main focus of this paper has concentrated on the empirical issues involved in conducting research in a male prison.

Conducting empirical research in prisons requires attention to both cultural/institutional issues and also issues specifically involved in the process of research interviewing. At an institutional level the male researcher has to develop non-collusive strategies for coping with sexism, and misogyny, whilst at the same time not appearing to be constantly at odds with the prison environment. Directly confronting institutionalised sexism may cause a research project to be terminated. At an individual level, in the research interview, direct confrontation of sexist attitudes and beliefs may prevent the extent and pervasive nature of such attitudes from emerging. To listen, to record and, in publication, to critique dominant male practices from a clear and explicit standpoint may be a positive way forward for further research. 


\section{Notes}

[i] Here, I am using the phrase in the way defined by Goffman (1970; p. 11) 'A total institution may be defined as a place where a large number of like-situated individuals, cut off from wider society for an appreciable period of time, together lead an enclosed, formally administered round of life.' Although not physically cut off from society, I would include the police within the scope of Goffman's definition.

\section{References}

Becker, H. (1967). "Whose Side Are We On?" Social Problems 14(3): 234-247. Bottoms, A. (2000). The Relationship between Theory and Research in Criminology. Doing Research on Crime and Justice. R. D. King and E. Wincup. Oxford, Oxford University Press.

Butler, J. (1989) Gender Trouble: Feminism and the Subversion of Identity, London and New York: Routledge.

Butler, J. (1993) Bodies that Matter: on the discursive limits of "sex", New York and London: Routledge.

Carrabine, E. and B. Longhurst (1998). "Gender and Prison Organisation: Some Comments on Masculinities and Prison Management." Howard Journal of Criminal Justice 37(2): 161-176.

Clatterbaugh, K. (1998). 'What Is Problematic about Masculinities?' Men and Masculinities 1(1): 24-45. 
Cohen, S. (1998). Intellectual Scepticism and Political Commitment: The case of Radical Criminology. The New criminology Re-visited. P. Walton and J. Young. Basingstoke, Macmillan: 98-129.

Colton, M., \& Vanstone, M. (1996). Betrayal of Trust: Sexual Abuse by Men who Work with Children. London: Free Association Books.

Connell, R. W. (1995) Masculinities, Cambridge: Polity Press.

Cowburn, M. (1990) 'Work with Male Sex Offenders in Groups.' Groupwork, 3, $157-171$

Cowburn, M. (1993) 'Groupwork Programmes for Male Sex Offenders: Establishing Principles for Practice' In Brown, A. and Caddick, B. (Eds) Groupwork with Offenders, London: Whiting \& Birch.

Cowburn, M. (1998). 'A Man's world: gender issues in working with male sex offenders in prison.' Howard Journal 37(3): 234-251.

Cowburn, M. and Modi, P. (1995) 'Justice in an unjust context: Implications for working with adult male sex offenders' In Ward, D. and Lacey, M. (Eds.) Probation Working for Justice London: Whiting \& Birch.

Cowburn, M. (2005). "Hegemony and discourse: reconstruing the male sex offender and sexual coercion by men." Sexualities, Evolution and Gender 7(3), 215-231.

Crawley, E. (2004). Doing Prison Work: The public and private lives of prison officers. Cullompton, Devon, Willan Publishing.

Equal Opportunities Commission (1995) Prison Officer wins $£ 15,000$ Settlement from Home Office London: Equal Opportunities Commission. 
Genders, E. and Player, E. (1989) Race Relations in Prisons, Oxford: Oxford University Press.

Genders, E. and Player, E. (1995) Grendon: a Study of a Therapeutic Prison, Oxford: Oxford University Press.

Goffman, E. (1970) Asylums, Harmondsworth: Penguin.

Harding, S. (1991) Whose Science? Whose Knowledge? Thinking from Women's Lives, Milton Keynes: Open University Press.

Hearn, J. (1998) 'Theorizing men and men's theorizing: Varieties of discursive practices in men's theorizing of men' Theory and Society, 27, 781-816.

Hearn, J. (2004). "From hegemonic masculinity to the hegemony of men." Feminist Theory 5(1): 49-72.

Jefferson, T. (2002). "Subordinating hegemonic masculinity." Theoretical Criminology 6(1): 63-88.

Kelly, L. (1988) Surviving Sexual Violence, Oxford: Polity Press.

Liebling, A. (2001). "Whose side are we on? Theory, Practice and Allegiances in Prisons Research." British Journal of Criminology 41: 472-484.

Liebling, A. and B. Stanko (2001). "Allegiance and Ambivalence: Some Dilemmas in Researching Disorder and Violence." British Journal of Criminology 41: 421-430.

Martin, S. and N. Jurik (1996). Doing Justice, Doing Gender. London, Sage. Morris, T., Morris, P. and Barer, B. (1963) Pentonville: A Sociological Study of an English Prison, London: Routledge and Kegan Paul. 
Pease, B. (1997) Men and Sexual Politics, Adelaide, South Australia: Dulwich Centre Publications.

Pease, B. (2000) Recreating Men: Postmodern Masculinity Politics, London: Sage.

Pickering, S. (2001). " Undermining the Sanitized Account. Violence and Emotionality in the Field in Northern Ireland." British Journal of Criminology 41: 485-501

Scully, D. (1990) Understanding Sexual Violence: A Study of Convicted Rapists, Cambridge, Mass, London: Unwin Hyman,.

The Industrial Tribunals (1995). Mrs P. Hoare v Home Office \& Anthony Hunt. Manchester, The Industrial Tribunals.

Westmarland, L. (2001). "Blowing the whistle on police violence: gender, ethnography and ethics." British Journal of Criminology 41: 523-535. 